THE USE OF ANIMATION TO IMPROVE ART EDUCATION

ANDREW STEVEN BOHART

A MAJOR RESEARCH PROJECT SUBMITTED TO THE FACULTY OF GRADUATE STUDIES

IN PARTIAL FULFILLMENT OF THE REQUIREMENTS

FOR THE DEGREE OF

MASTER OF COMMUNICATION AND CULTURE

FACULTY OF GRADUATE STUDIES IN COMMUNICATION AND CULTURE RYERSON UNIVERSITY

TORONTO, ONTARIO 


\begin{abstract}

\section{THE USE OF ANIMATION TO IMPROVE ART EDUCATION}

\author{
Master of Communication and Culture 2008
}

Andrew Steven Bohart

Faculty of Graduate Studies in Communication and Culture

Ryerson University

In this major research project, I explore the ways in which animation can be developed to improve art education. I developed an animated short film titled The Art Collector as an educational tool that incorporates computer animation technology with art theory, to educate about art theory and art history in a unique way through paintings from three different surrealist artists: Salvador Dali, René Magritte and Max Ernst. I also provide some background information as to how this animation project came to be, including the development of the script, the main character, and the animation itself. I draw upon several studies that illustrate the ways in which animation can be used successfully as an education tool to motivate student learning. 
Dedication Page

For Kelly 


\section{Acknowledgments}

I want to thank Michael Murphy for his insight and close reading of my project and his helpful suggestions regarding my animation. I also wish to thank Jerry Durlak for providing his feedback on this project, Ed Slopek for his thoughtful response to my work and Richard Grunberg for agreeing to chair my committee. I want to thank Karleen Pendleton Jiménez for her close editing of my work. Thanks to Kelly Young for her discussions and suggestions regarding the animation and her input on the art curriculum and most of all, for always believing in me. Finally, I wish to thank my family for their constant love and support. 


\section{Table of Contents}

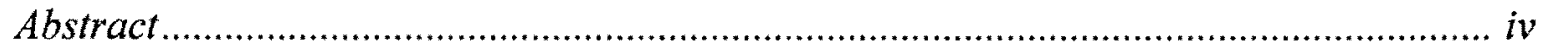

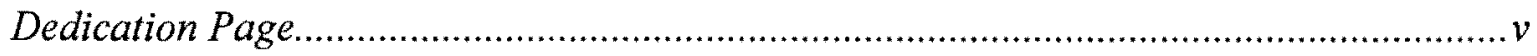

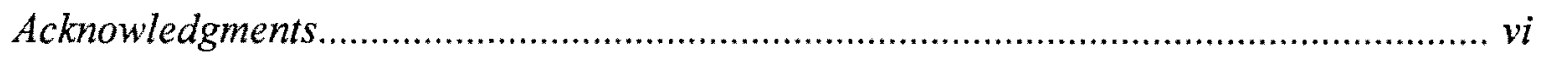

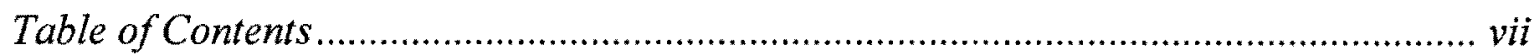

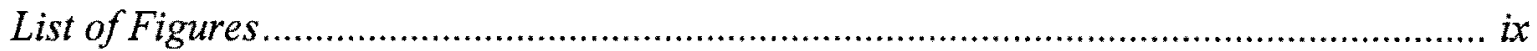

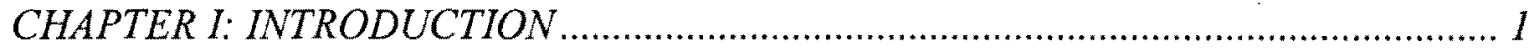

Background of the Study: ConteXtualizing PoINTS of INFLUENCE ............... 3

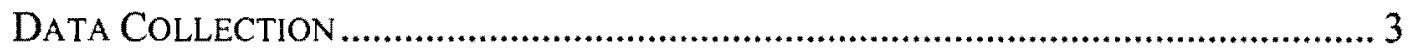

CHAPTER II: COMPUTER ANIMATION AS A DOUBLE EDGED SWORD ................... 6

COMPUTER ANimation SOFTWARE In CANADA: AN HistoriCal OVERVIEW ........ 7

PERFORMANCE ANIMATION ......................................................................... 14

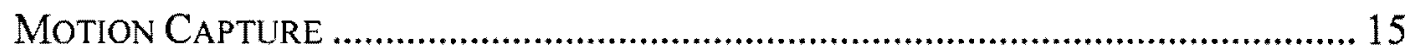

A Movement Beyond Photo Realistic Animation ....................................... 17

CHAPTER III: THE USE OF ANIMATION AS AN EDUCATIONAL TOOL ................ 21

REgulatory Policy For CHILdREN'S TELEVISION ....................................... 22

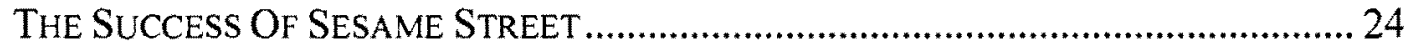

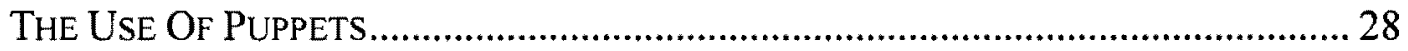

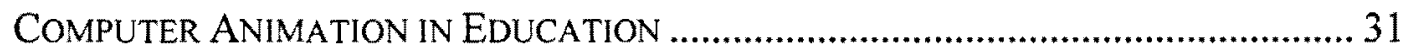

Photorealistic Graphics as a MEANS to Understand ART ........................ 35

CHAPTER IV: THE ART COLLECTOR: ANIMATION AND THE ONTARIO

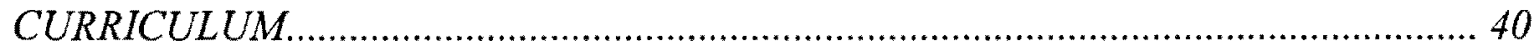

THE ART COLLECTOR ANIMATION SCRIPT ......................................................... 40

THE ART COLLECTOR: PROCESS AND DEVELOPMENT .......................................... 49

SURREALISM AND THE ART COLLECTOR PROJECT ............................................... 54

A VISUAL ART UNIT: UNDERSTANDING SURREALISM ....................................5 56

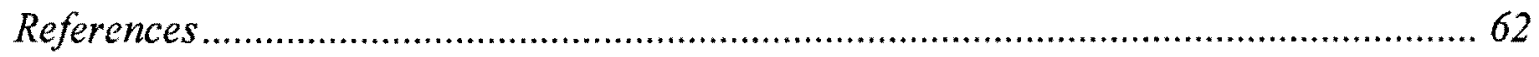




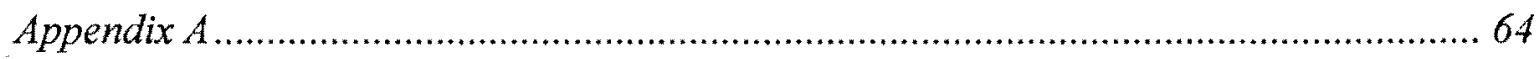

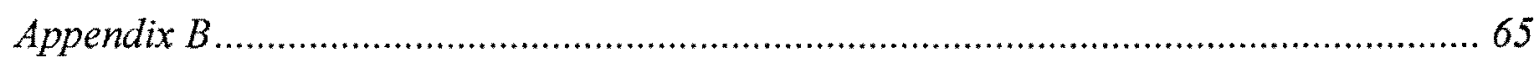

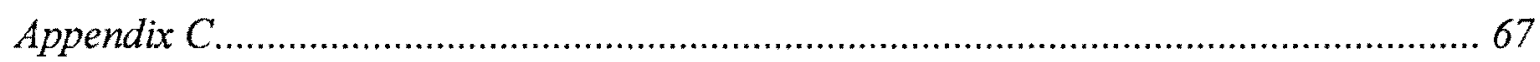




\section{List of Figures}

Figure 1: The Art Collector: "Persistence of Memory 1".............................50

Figure 2: The Art Collector: "Persistence of Memory 2"..............................51

Figure 3: The Art Collector: "Surrealism and Painting 1"

Figure 4: The Art Collector: "Surrealism and Painting 2" .............................52

Figure 5: The Art Collector: "The False Mirror 1".....................................53

Figure 6: The Art Collector: "The False Mirror 2"...................................53

Figure 7: The Art Collector 3-D Animation...........................................55

Figure 8: The Art Collector 2-D Animation...........................................56 


\section{CHAPTER I: INTRODUCTION}

In this major research project, I explore the ways in which animation can be developed to improve art education. My interest in this work stems from a computer animation course I attended at the International Academy of Design (IAOD) in 2000. This program was an intensive nine-month course that provided a solid understanding of three-dimensional computer animation using the animation software package Softimage. Many of the students in my class were in their late teens or early twenties. What I found particularly interesting with this age group was that they were fixated on trying to recreate realistic models and sets using the high-end animation program. Although many of the students were still trying to grasp the basics of the animation program, they were obsessed with creating realistic models, textures, lighting and animation in a similar fashion to what you would find in a multimillion-dollar feature film.

It was interesting to note that established computer animation artists, who were also our instructors, unanimously agreed that computer animation technology enabled artists to tell stories more creatively and expressively than through film or video. However, many of my fellow studerits became constrained by this same technology as they used the animation software to try to emulate reality, as opposed to using technology to find their own expressive style. This focus on realism did not stop with the students, as students who were able to accomplish a greater sense of realism in their work tended to get better grades in their modeling, rendering, and animation classes. Therefore, even though the established artists imagined new creative possibilities, they contributed to the 
constraining of 3D by rewarding those students who emulated reality. I believe that the instructors looked for realism in a computer animation student's work as a means of judging whether they have mastered the animation software. The 3D technology, and the privileging of realistic uses of the technology guided the artists' imaginations and creative works.

When I began this major research project, I proposed to investigate the ways in which computer generated 3-D animation can be used as a creative tool to enhance student learning. However as I worked on my animation projects, I discovered that by looking at various forms of art such as painting, film, and photography in addition to animation, technology clearly played and continues to play a large role in the development of new forms of art, as well as influencing artistic styles. For example, animation was first successfully developed in $1906^{1}$ and is therefore, still a relatively new artistic medium. Nevertheless, animation styles have evolved considerably over the last century. For example, characters in early animation sequences were somewhat hard and awkward looking. As animation artists began to master this new art form, the characters began to look more childlike and the animation became more refined. The entire style of the animation changed. The style of animation changed considerably once again with the development of 3-D animation. Digital technologies continue to expand all forms of art into a wider-ranging direction.

\footnotetext{
${ }^{1}$ http://animation.filmtv.ucla.edu/program/anihist.html Retrieved October 15, 2007.
} 


\section{Background of the Study: Contextualizing Points of Influence}

Within the last century however advances in technology have become a major factor in bringing about change in both artistic style, as well as in our thinking of what can be "considered" art. New forms of technology such as photography, film, video, computers, computer graphics, the Internet and various forms of digital media have all influenced the way we create, understand and view art.

My interest in technology is situated in how technology mediates our experience. In order to ground my analysis, I developed an animation short titled The Art Collector (Bohart, 2004), that explores the surrealistic art movement through an engaging storyline. The Art Collector is the major component of this project that serves as a concrete example of the ways in which animation can be used to enhance an educational unit.

\section{Data Collection}

There are a number of sources used in this major research project. The first is empirical data obtained from case studies that explore how technology, such as 3-D computer animation, can be used successfully as a teaching aid in the classroom. Second, by exploring the ways in which technology influences styles of art in $17^{\text {th }}$ century painting, $19^{\text {th }}$ century photography and film, and $20^{\text {th }}$ century forms of animation, my study spans three centuries. It is useful to see a connection among painting, photography, film and animation being located in a wider frame where visual art is developing. Finally, I offer my animated short as a practical example of the ways in which technology can be developed as an educational resource to teach about visual art through the medium of computer animation. 
In chapter two, Computer Animation as Double Edged Sword, I begin with a brief history of the computer animation software industry in Canada. I investigate the influence computer technology has had on the animation industry, as well as the role animation software plays in the look or style of animated films. I also examine the impact that threedimensional computer animation has had on traditional animated films. More specifically, this chapter focuses on how computer animation software has been largely responsible for a shift away from the wide variety of "cartoony" artistic styles of the 1960 's to the current trend of hyper-realistic three-dimensional animation in more recent films.

In Chapter Three, The Use of Animation as an Educational Tool, I examine the educational television program for children, Sesame Street, in order to understand what makes this show so unique. I begin this section with an historical account of regulatory policy of children's television programming and objectives as well as the implementation of the United States government's Children's Television Act (CTA) of 1990. In the final section of this chapter, I review the results of two research studies to illustrate how effective the integration of three-dimensional computer generated imagery (CGI) can be used as an alternate mode of learning, within the classroom environment (Choi Ju \& Cifuentes, 2002; O'Neill, 2000). The results of these research studies prompted me to develop my own educational animated film titled, The Art Collector (Bohart, 2004).

Finally, in Chapter Four, The Art Collector: Animation and The Ontario Curriculum, I discuss the process of developing my animated short film project, The Art Collector, and provide an example of the ways in which this animation short could be incorporated 
into the existing intermediate public school curriculum through a lesson/unit plan. The purpose of The Art Collector project is to provide a practical educational tool that incorporates computer animation technology with art theory, to educate about art theory and art history in a unique way through paintings from three different surrealist artists: Salvador Dali, René Magritte and Max Ernst. In the latter half of chapter four, I offer future considerations for research and practice, by considering the larger concept behind The Art Collector project, the development of a series of animated shorts, each exploring a different style of visual art. I provide some background as to how this animation project came to be, including the development of the script, the main character, and the animation itself. I illustrate how the final version of The Art Collector has differed slightly from the original concept. Since the two studies in chapter three indicate that animation can be used successfully as an education tool to motivate student learning, I consider the future educational possibilities that The Art Collector as a motivating tool in a visual art curriculum might offer (Choi Ju \& Cifuentes, 2002; O'Neill, 2000). 


\section{CHAPTER II: COMPUTER ANIMATION AS A DOUBLE EDGED SWORD}

Animation is a means to reach the fantastic - the dreamlike - the far out. It can do everything that cannot be made in live action. It is a field that has hardly been scratched at the surface as yet. (Foldes, 1972, p. 204)

Animation is defined as "...the action of imparting life..."(The Oxford English Dictionary, 1989 , p. 84). The meaning of the term impart implies 'giving life' to something. In the field of animation, giving life to something inanimate involves an imaginative process on behalf of the artist-animator. Animator Peter Foldes (1972) suggested that animation was a way of going far beyond reality to reach the "fantastic" (p. 204). With the introduction of computers to the field of animation, a tool was created whereby animators could even move beyond the confines of traditional animation techniques. However, over thirty years after Foldes made his statement about traditional animation, the majority of computer animators continue to move toward photo-reality. Although the creative potential that computer animation provides is limitless, computer animators are still trying to produce animation that emulates reality.

Imitating reality through computer animation is the focus of this chapter, which encompasses three sections. The first section will provide a brief historical overview of the growth and development of computer animation technology in Canada from the 1960s to present. In the second part, an overview of a new style of performance animation called motion capture will be presented. In the final part of this chapter, I will 
argue that the use of the computer for animation can be compared to a double-edged sword. On the one hand, computer animation technology has added new life into the established artistic medium of animation. On the other hand, the field of computer animation technology has created a trend toward photo-realistic animation, which is curbing the seemingly limitless possibilities of using animation as a means of artistic style and expression in unrealistic ways.

However, I believe that the current western trend of photo-realistic animation will shift toward a new artistic style of animation whereby artist's creativity (of style) is once again the main focus. Unlike photo-realistic animation that "Western" audiences are growing tired of, the new computer animation movement that I am predicting in this chapter will somewhat resemble that of the $19^{\text {th }}$ Century Impressionist movement. I will use Dr. Seuss' (1990) How the Grinch Stole Christmas to illustrate how abstract animation continues to be enjoyed by a "Western" audience. I will compare how Dr. Seuss' story was received by its audience in book form, abstract traditional animation form, and then as a live-action/computer animated feature film.

\section{Computer Animation Software in Canada: An Historical Overview}

Since the early 1920 s there has been an incredibly diverse range of styles and techniques used to create animation. Techniques such as traditional hand-drawn cell animation, the manual manipulation of various media such as cutouts, silhouettes, sand or string on glass, and stop-motion animation have all met with success. Each of these methods has their own unique attributes. The medium chosen by an animator is directly related to the look, feel and style of the final production. 
It has been widely believed that the illusion of movement found in animation, film and video is based on the phenomenon known as the persistence of vision. This theory proposes that the human brain retains an image for a split second after the eye actually sees it. By placing still images in rapid succession, the brain overlays these images by blending them together. The resulting illusion is that the separate still images appear as a continuous stream of movement to the viewer. ${ }^{2}$

Traditional animation relies on an artist, or more often, group of artists to accurately draw individual pictures of a figure or object in motion. These separate pictures are then photographed in succession on one continuous piece of film using a motion picture camera. Much of the traditional or classical animation process was pioneered and perfected by Walt Disney and Walt Disney Studios. Although this method previously produced and continues to produce effective results, at 24 frames per second of screen time, traditional animation is extremely time consuming, labour intensive, and expensive to produce. Many of the early animation studios experimented and perfected a means of increasing their workflow and production time through a method called key-frame animation. Through key-frame animation, a senior animator would draw the pictures where the animated character had the most expressive action positions, called keyframes. A Junior Animator (or a team of Junior Animators if the budget permitted) then had the arduous task of drawing all the images in between these key-frames.

${ }^{2}$ http://encarta.msn.com/text_761569450_1/Motion_Picture.html Retrieved January 6, 2007. 
The introduction of computers into the traditional field of animation in the last half of the $20^{\text {th }}$ Century revolutionized the ways in which artists produced animation. Moreover, the use of the computer in the production of animation was first conceived by animators working in the field, as a means of reducing the amount of drawing for the animator. Traditional animation as 'time consuming' is explained by Foldes:

The lone filmmaker, like myself and most Europeans, suffers from the inevitable slowness of repetitive work. I cannot produce more than two to three minutes a month alone. This is why I have recently got interested in working directly with computers, which can take a large amount of complicated quantitative work off the creative artist's shoulders. (cited in Russett \& Starr, 1976, p. 204)

The technology revolution proceeded and as computers became more sophisticated, advancements in computer software enabled artists to work and create images directly onto the computer screen. Over the past decade, the processor speed, memory and graphics capabilities of personal computers have increased tremendously while the cost of this technology has become more affordable for the general public. This has allowed a larger number of budding artist/animators to create their own computer animation.

In 1968, Nestor Burtnyk and Marceli Wein were working for the National Research Council in the area of computer applications development and thought an ideal use of the computer would be to replace the junior animator in 'tweening' or creating the in-between 
frames of an animation sequence. During an acceptance speech for an achievement award in 1996, Dr. Wein stated:

While we weren't ourselves animators, we were interested in providing tools for artists. At that time, there weren't commercial computers available; we built everything, including the first computer mouse in Canada, at NRC. No programming was involved. It was all done through a menu approach. We were clearly pioneers in this area. ${ }^{3}$

The first test animation using this technique was called Metadata and was created by Foldes as he pioneered a new technique of animating by drawing freehand directly onto the monochrome CRT display using a light-pen. While working for the National Film Board of Canada in Montreal, Foldes again used the NRC's computer animation system to create a ten minute animated film called Le Faint/The Hunger in 1974. This was the first computer-animated film production to be nominated for an Academy Award (Weinstock, 1986, p. 39).

Toronto native John Pennie, realized early on that the future of film and television lay in computer animation technology. In the early 1970's Pennie co-founded Image West in California, one of the first studios to specialize in computer animation. By 1976, Image West held approximately $25 \%$ of the total computer animation market. Although several industry professionals understood the importance computer animat:on would have in the

\footnotetext{
${ }^{3}$ http://www.nrc.ca/corporate/english/media/news/n_anim_e.html Retrieved July 2, 2003.
} 
future, Pennie stated that in the early days of computer animation: "Most of the film industry and television producers did not take computer animation seriously at the time because of the limitations in analog technology" (cited in Mazurkewich, 1999, p. 244).

Pennie split from Image West over creative differences and in 1982 founded Omnibus Computer Graphics in Toronto. Omnibus provided research funding to the New York Institute of Technology Computer Graphics Laboratory (NYIT) for research and development of computer animation software. In exchange, Omnibus received exclusive licensing rights for the software NYIT was developing. Pennie assembled an ambitious team of animators and programmers at Omnibus consisting of: Will Anielewicz, Paul Breslin, Doug MacMillan, Greg Hermanovic co-ordinator of in-house programming, and Kim Davidson who was in charge of developing Omnibus' proprietary source code called the PRISMS software program. By the mid-1980's, Omnibus had surpassed Image West in production output and was the hottest computer animation company in North America. In 1986, Omnibus bought its two largest competitors: Digital Productions and Robert Abel and Associates. Now Omnibus was poised to become the largest animation company in the world. When Omnibus purchased the two companies, Robert Abel and Associates was $\$ 12$ million in debt. Omnibus was planning a share offering to help finance the deals, but when the share offering was delayed, the banks foreclosed and Omnibus went bankrupt.

With Omnibus out of business, its employees found work elsewhere and several started their own companies. Two of Omnibus' veterans, Greg Hermanovic and Kim Davidson acquired the PRISMS source code and by 1988 had founded Toronto-based 
animation software company Side Effects Software. Side Effects has become a leader in animation software with their powerful computer animation package called Houdini (Mazurkewich, 1999, pp. 278-280).

Another Canadian computer animation software success story is Alias/Wavefront. In 1982, Steven Bingham and Susan McKenna were developing a computer-animated television show and approached Omnibus to produce it. Bingham and McNenna couldn't afford Ominbus' steep price tag and decided to develop their own simpler 3-D computer package. They founded Alias Research (now Alias/Wavefront) in 1984 and hired several animators and programmers including Dave Springer, Mike Sweeney, Rob Kreiger and Will Anielwicz of Omnibus.

Alias' first computer animation software version was not nearly as powerful as other animation programs, however, the quality of the rendered images it was able to produce was superior to anything else on the market. General Motors was so impressed with Alias' software that they bought the program (still in its beta version) for their automotive design team. With such a large company as their first client, Alias focused their attention on perfecting the modeling component of the program. Even today, Alias' most recent animation package Maya is one of the most widely used modeling software packages.

Another professional animation package is Softimage of Montreal. In 1979, Daniel Langlois was working as an animator for the National Film Board of Canada's French Animation Unit. Two producers of French animation, Robert Forget and Rene Jodoin, provided financing and energy to the National Research Council and to the university of Waterloo to aid in the development of early computer animation. 
Daniel Langlois was hired to design and co-direct a short film called Tony De Peltrie in 1985. Tony De Peltrie was produced by Pierre Lachapelle and directed by Pierre Lachapelle, Philippe Bergeron, Pierre Robidoux and Daniel Langlois. This film was a significant milestone in the field of computer animation because it was the first time a believable human character had been successfully computer-generated in 3-D. This film won several awards, however, it took four programmers over three years to produce the eight-minute film. ${ }^{4}$ With his background in graphic design, Langlois felt that a more artist-friendly program needed to be developed in order to make computer animation more efficient and accessible to traditional animators.

Langlois left the NFB and in 1986 founded Softimage. Creative Environment was Softimage's first commercially available animation program and was an instant hit with artists/animators because it was more intuitive to work with than many other programs on the market. In 1991, Softimage launched a new version called Actor, in which Softimage added an inverse kinematics feature. Inverse kinematics provides the computer with information on muscular movement and human/animal physiology. Through inverse kinematics, when an animator moves a character's upper arm, the lower arm, wrist, hand and fingers will follow in a natural movement. Now, instead of the animator having to move each individual body part separately, they only had to move the main parts they wanted to move. This was a considerable time saver and other animation packages soon

${ }^{4}$ http://www.adventuresinanimation.com/TonydePeltrie_htm Retrieved February 20, 2006. 
followed suit. Softimage launched its newest software package called XSI in 2000 and is still considered one of the top professional animation programs on the market.

The experimental animation expertise of the National Film Board of Canada and the research and development expertise of the National Research Council formed the catalyst for the strong computer animation software presence we enjoy in Canada today (Mazurkewich, 1999, pp. 282-288). Computer animation software was initially developed to aid in the process of creating traditional animation. This software has had an enormous impact on many other industries as well. Product design, video game design, crime scene re-creation, the pre-visualization of live action television and feature films, and special effects creation and compositing are just some of the industries incorporating computer animation.

Traditional animation has always been thought of as 2-D animation or twodimensional animation. Although many hand-drawn animated films used 3-D principles such as perspective and representational lighting through highlight and shadow, these animated films still looked flat to the viewer. The dimensions of height and width were well defined, however it was difficult to convince/fool the viewer into seeing the third dimension of depth.

\section{Performance Animation}

The advent of computers created a means to calculate a rapid succession of complex mathematical computations. In order to understand how a computer animation program creates an image in 3D we need to visualize an imaginary box. This box has a grid running through each of the three axes of; height, width, and depth. Each grid is given a 
letter so the computer knows where to define or place an object within this imaginary "box". The axis or grid running horizontally through the box's width is the " $x$ " axis, the axis running vertically through the box's height is called the " $y$ " axis and the axis running through the third dimension of depth is called the "z" axis. Where all three of these axes meet is called the " 0 " point or (X equals 0 , Y equals 0 , and $\mathrm{Z}$ equals 0 ).

Using this principle, the computer animator can place points anywhere within this imaginary box and the computer calculates an $\mathrm{X}, \mathrm{Y}$, and $\mathrm{Z}$ co-ordinate for the point. By connecting these points with vertices, or line segments, an animator can create a limitless number of models. In order to animate these models, the element of time must also be added. The computer can then calculate the placement of the model at a given point in time. Calculating the particular location of an object at a particular time and then creating a three-dimensional image from this data is the process known as rendering. Playing back these rendered images in rapid succession, creates the illusion of movement in a three dimensional environment.

\section{Motion Capture}

In 1916, animator Max Fleischer developed a device that projected individual film frames onto paper so that an animator was able to trace cartoon characters over photographed frames of live performers. Fleisher called his device the Rotoscope. This was the first time that a real-life performance was used to help create an animated character. Although this animation technique increased productivity, the cartoon character's movements appeared too realistic and the animation lost some of its humour. 
Rotoscoping was used successfully in several Disney films such as Snow White ("Walt Disney", 1937) and Sleeping Beauty ("Walt Disney", 1959).

Motion capture is a technology that has quickly become widely used in the field of animation. Motion capture, also known as performance animation, is similar to Max Fleisher's rotoscoping technique. Motion capture is the term given to the process of recording the movement of an animal, person or object in real-time and converting this data into information a computer can process. The computer can then transfer this movement data onto a computer-generated character to create extremely realistic action. Motion capture has the same problems and limitations as rotoscoping in that the movement is too realistic for funny cartoon characters.

There are many parallels between rotoscoping and motion capture. After these two technologies were invented, many people believed that both rotoscoping and motion capture would replace traditional animators and computer animators respectively. Neither of these methods was widely accepted at first as animators considered these methods a form of "cheating". While rotoscoping was never used extensively, motion capture has become a hot technology in areas separate from the Bugs Bunny "cartoony" style of animation. Motion capture is being used successfully in video game design, live action stunts for film and television, and for various simulation programs. The film Final Fantasy (2000) made extensive use of motion capture throughout the film. Like the rotoscope, motion capture will eventually become just another style tool (Menache, 2000, pp. xii-xiv). 


\section{A Movement Beyond Photo Realistic Animation}

Animation is a unique communication medium because it allows the artist to tell a story without being confined to the laws of reality. Animation allows for the possibility of characters and environments that are unrealistic. Animals with humanistic attributes, surreal environments and exaggerating the laws of physics are all possible through animation. The use of computers could potentially support an artist's creativity, but does not replace an artist's imagination. In his own early trials regarding the use of the computer as an aid for animation Foldes (1972) writes:

...it became soon evident that computer-aided animated films will not replace the handmade ones. The computer is able to do other things - help to create other styles, other movements than the human hand. So I firmly believe that computer-made, or rather computer-aided, animation will simply enlarge the field and produce new creative possibilities, without harming hand animation. I think the expression computer-aided film is correct, because no computer will do anything without human will. (p. 204)

From this quote, it is clear that there is a place for computer animation that is quite separate from traditional 2-D animation. Nevertheless, computer animators can be so engrossed in the technology that its influence feels excessive. In the previous section I provided a brief overview of the history of computer animation that clearly highlights how the introduction of computers into the field of traditional animation has had many 
positive effects on the production of animation. Having said this, it is also important to consider how computer animation that pushes toward photo-realism could potentially evolve and move beyond realism because Western audiences might grow tired of the realistic and move toward the abstract.

During an interview with computer animator Steve Williams of the special effects studio Industrial Light and Magic, Mazkewich (1999) writes:

On the one hand, Williams is hoping for a Ren \& Stimpy revolution in the CGI world. On the other, he warns that the industry is relying too heavily on special effects thrills. He refers to the crasser features as "tornado porn" and predicts that people will eventually get sick of effects films. (p. 296)

In a sense, Williams is describing the double-edged sword created by the contribution of computer technology to traditional animation, as he suggests that too much of one effect may lead an audience to boredom. Furthermore, by using the metaphor of a doubleedged sword, I will illustrate how Artist-Animators have become caught up in the technology and are not letting their ideas flow freely. Computer animation technology as a 'double-edged sword' can be seen as a possible interference in the process of creativity.

Although there are many examples that can be used to illustrate how photo-realistic computer animation may lead to a disengaged audience, I will limit my example to Dr. Seuss' How the Grinch Stole Christmas. The success of the children's book How the Grinch Stole Christmas was based on an interesting story, the abstract nature of the imaginary location of 'Whoville,' together with the surreal characters. The abstract and 
imaginative quality of this story and pictures was entirely its success. The creative story line as well as the unrealistic portrayal of characters and landscape helped to engage the reader. The twenty-minute traditional animation adaptation that followed, directed by cartoon legend Chuck Jones, retained the same abstract techniques as the book and was similarly well received by its audience.

The feature-length live-action film adaptation of How the Grinch Stole Christmas was not nearly as receptive by its audience in part, because of this photo-realistic style. In addition, the story became too long once it was expanded from Chuck Jones' 20 minute portrayal to a two-hour film.

Although computer animation technology has added new life into an established artistic medium of hand drawn animation, I predict there will be a movement beyond the current trend of photo-realistic animation. This new movement will explore the limitless possibilities of using computer animation as a tool to express artistic style and creativity.

The impressionist movement stemmed from artists becoming dissatisfied with the idea that $19^{\text {th }}$ century society wished to have art that emulated reality. Technological advances in the field of still photography around this time meant that a technician, for they were not really considered artists at this time, could capture an instant in time and essentially satisfy the human quest for representational reality. Artists of the time were frustrated with simply representing reality. They felt the need to express how the world made them feel, or their unique impression of the world. This was the birth of Impressionism. This same scenario is taking place today in the artistic stream of animation. In a similar fashion to the birth of photography, the technology behind 
computer animation has allowed artists to create an astonishingly photo-realistic representation of the world around them. Like the innovators of the impressionistic movement, the truly visionary present-day computer artists appear to be growing dissatisfied with merely representing reality. I believe that they will combine the computer technology's ability to develop the synthetic with Impressionism to create a new trend within a genre of animation as a movement that might be called "Synpressionism" or Synthetic Impressionism. Toronto based computer animator Chris Landreth is at the forefront of this new trend. Several of Landreth's animated shorts such as; The End (1995), Bingo (1998) and Ryan (2004) use 3D computer animation software in innovative and creative ways. Both the film critics and the public have positively received the creative use of digital animation in Landreth's independent films. The movement of computer-generated animated films from simply realistic special effects to more of a true art form in its own right, has already begun. 


\section{CHAPTER III: THE USE OF ANIMATION AS AN EDUCATIONAL TOOL}

Wry amusement at the thought that all this enormous effort and the substantial funds involved may be frustrated by the determined little fouror five-year-old who, the minute his mother's back is turned, slips up to the TV and switches it to the cartoons. This is the challenge: can a group of the most talented and creative adults that effort and money can put together get the attention of the preschooler long enough to teach him something? -Alan Pifer, President Carnegie Corporation of New York, March 1968. (Polsky, 1974, p. 38)

In this chapter, I examine the complexities of developing educational television programming for children. My interest in educational children's media led to my development of the educational resource entitled The Art Collector (Bohart, 2004). The purpose of this animated short is to enhance a lesson and/or unit about various styles of visual art using Macromedia's Flash MX computer animation software. My animation project builds upon several research studies and successful educational television programs that illustrate the importance of incorporating animation as an educational resource for children. My inquiry begins with an historical account of regulatory policy of children's television programming, objectives and implementation of the United States government's Children's Television Act (CTA) of 1990. I then explore the original objectives of Sesame Street, one of the longest running children's educational programs 
to determine the important qualities that have made the show successful. Finally, I offer The Art Collector, my own computer animated short as an additional example of how the effectiveness of incorporating computer generated imagery (CGI) can be used as an alternate mode of learning for children.

\section{Regulatory Policy For Children's Television}

One of the most important pieces of regulatory policy on the issue of children's educational television was the United States government's legislation of the Children's Television Act (CTA) of 1990. This legislation required broadcast stations to provide educational and/or informational children's programming during their regular broadcast day. More importantly, when their broadcasting licenses came up for renewal, the broadcasters were required to demonstrate to the Federal Communications Commission (FCC), the federal government body that grants licenses to television stations, the amount of the educational content they provided to children.

The CTA was initially written in such a way that made it easy for broadcasters not to take the law seriously. For instance, the amount of educational content required by broadcasters was not spelled out clearly. In addition, the content that was considered to be educational and iniormational was ambiguous. It was not until the children's educational advocacy group called the Center for Media Education (CME) convinced the United States government to re-examine the Act, that new requiremonts were added to give the Act more control over broadcasters. The Act required an examination into broadcasters' license renewals. Moreover, they repeatedly published outlandish claims of what broadcasters were trying to consider as educational children's television programs. 
For example, broadcasters tried to convince The Federal Communications Commission (FCC) that shows like The Jetsons, Leave it to Beaver and G.I. Joe should be considered educational content (Aufderheide, 1994, p. 23). By 1993, partially as a result of publishing these educational claims, broadcasters began taking the CTA seriously and started adding educational shows they termed "FCC friendly" to their line-up.

A central reason for the broadcasters' resistance to adopt educational and informational programming is that a purely entertainment-based children's show was able to generate more sponsors for advertisements than an educational show. Prior to 1984, the FCC prevented program-length commercials or advertisements for children's products. In 1984, these regulations were lifted and toy manufacturers immediately seized upon this opportunity.

Toys such as "Transformers", "My Little Pony" and "He-Man" suddenly had their own spin-off animated television series as a means of promoting the products. What broadcasters of the 1980s and early 1990s all seemed to agree upon was that the FCC failed to realize that children simply were not interested in watching educational programming. Television syndicator Howard France, best summed up the sentiments of other broadcasters, television producers and syndicators of the early 1990s:

The FCC is telling you, you have to put boring TV on - the primary focus has to be educational, not entertaining ...you know kids, they don't want to go to school all week. If they don't want to watch it, who's going to make 'em? The government can't pass a law to make people watch shows. (Aufderheide, 1994, p. 29) 
Jenny Trias, head of children's programming at ABC during the mid 1990's, provides a good understanding of what broadcasters are thinking, concerning educational programming for children, as she states:

I've done focus groups over my 15 years here, and I will always remember that one little boy said, 'I go to school Monday to Friday, Saturday morning is my time.' The most important thing should be entertainment, and if we can add educational elements, it's icing on top of the cake." (Aufderheide, 1994, p. 29)

In her article Why Kids Hate Educational TV (1994) Patricia Aufderheide indicates that the general consensus of children's programming among the television industry is that children are predestined to prefer entertainment over education and that you cannot have both in a successful show. Aufderheide, contends FCC regulators must do more in shaping the market conditions in order to foster the quality of educational programming the Children's Television Act had intended. A central theme that emerged while reading articles on regulatory policy was that the most important aspect to children's television programs was that they must be entertaining in order for children to initially want to watch. Determining what entertaining qualities of a show draw in young audiences is key in making educational programs marketable.

\section{The Success Of Sesame Street}

Sesame Street has been undoubtedly one of the most successful and long-running educational children's programs in the history of television. In order to understand the 
elements required for creating an educational program that is also entertaining, a close examination of the preliminary research and objectives that went into the development of Sesame Street would be instrumental. In his book Getting To Sesame Street, Richard Polsky (1974) provides a detailed account of why the show ultimately succeeded in capturing a large preschool audience and providing them with basic skills upon which to build their future education.

During the development of the Sesame Street series, the Children's Television Workshop identified four key requirements for capturing their target audience. First, the series had to be entertaining. A show with strong entertainment value would naturally attain and maintain the attention of the target audience of preschoolers so that they would initially want to watch the show. A second requirement, which ties in closely with the first, is that the show had to be interesting. A young viewer is easily distracted. Therefore, once the preschooler has begun to watch an episode of Sesame Street, it needed be interesting enough to hold the viewer's interest throughout the show. The third requirement for Sesame Street was that it must have a high educational value, the main objective being to prepare preschoolers for their first year of school. The final requirement was to add repetitive elements or themes to each episode. Repeating both visuals and audio of specific educational content improved the preschooler's memory retention. Barbara Finberg, an executive associate at Carnegie Corporation, the non-profit organization that initially provided the majority of the Sesame Street's budget, best describes the main objective of the Sesame Street series as she states: 
TV can reach children before they start nursery school, kindergarten, or Head Start, or can be used to enrich the preschool program itself. Large numbers of children, however, will not have the opportunity to attend a preschool program, whether their parents can afford to send them to a private nursery school or whether or not they are eligible for Head Start. This seems to us a chance to find out whether television, a medium that can reach more children than any other method presently available, can offer all children a head start on their education, open their lives to a wide variety of experiences, and make learning interesting and inviting. (Polsky, 1974, p. 8)

One of Sesame Street's concepts in capturing the attention of a young audience was the use of short "vignettes" of information. Today's generation of children increasingly grow up with television, and as such, they become accustomed to the fast pace and rapid editing techniques of current children's television programs and commercials. Critics of children's television programming include educators and media theorists, such as Neil Postman (1985) and Jane Healy (1990). They believe that the rapid bombardment of content/information, which children have come to expect, has been instrumental in the development of two generations of attention deficit children. Consequently, educators have found it increasingly difficult to attain and maintain the attention of their students long enough to teach them a lesson. 
In his book, Amusing ourselves to death, Postman (1986) analyzes the "Sesame Street" approach to educational television. Postman explains that initially, when the series commenced in 1969, Sesame Street was considered by both educators and parents to be a novel approach in introducing preschoolers to numbers and the alphabet, as well as a variety of concepts for social interaction. Most importantly, Sesame Street enabled preschoolers from economically impoverished backgrounds to see learning and education as something positive. After almost two decades of Sesame Street viewing, Postman surmises that Sesame Street only encourages children to enjoy school if school is structured in the same fashion as the television series. Postman surmises that a show like Sesame Street undermines the traditional idea of what schooling represents.

Postman makes several comparisons and contrasts between television and the traditional classroom. For example, the classroom is a place of social interaction while television viewing is done individually in the privacy of the home. Postman writes, "Whereas in a classroom, fun is never more than a means to an end, on television it is the end in itself" (p. 143).

Two central concepts are proposed in this chapter. First, Postman states that the main contribution television provides to educational philosophy is that teaching and entertainment are inseparable. He emphasizes this point as he believes that a consensus among educators is that children learn best when they are interested in what they are learning or, in other words, they learn best when they are entertained. The second concept Postman explores in this chapter is that, as with the steep increase in the amount of 
television being viewed by youth, a massive reorientation toward learning has been created. Postman writes,

The consequences of this reorientation are to be observed not only in the decline of the potency of the classroom but, paradoxically, in the refashioning of the classroom into a place where both teaching and learning are intended to be vastly amusing activities. (p. 143)

Postman acknowledges that Sesame Street has been one of the most successful educational children's programs to date. However, he provides a unique perspective in his explanation that Sesame Street is successful because the producers of the series understand that "television children" growing up in the 1960s, 1970s and 1980s have been conditioned to accept, and most importantly, expect television commercials as a form of entertainment, and the Sesame Street series has been modeled after a series of rapid television advertisements. In addition, the use of animals through animation and puppetry has served as a powerful technique for communication with children.

\section{The Use Of Puppets}

There is a deep-tooted connection between puppetry and children. The ability to bring an inanimate object to life can capture and hold the attention of a child to a much higher degree than the performance of a live actor. Producers of children's television programs understand the special captivation puppets have over children, which explains the high percentage of children's programs that incorporate puppetry into their shows. The ability 
of a puppet to suspend the audience's disbelief, as well as its friendly, cuddly and expressive nature, all contribute to an overwhelming acceptance of puppets by children.

In 1966 Joan Cooney was instructed by Carnegie Corporation to do a feasibility study to see what television should try to teach children. Cooney traveled across the U.S. and Canada to interview a number of cognitive psychologists, educators, and paediatricians. From these interviews, Cooney discovered the great potential of incorporating a variety of educational techniques including puppets and animation, as Polsky (1974) explains:

Mrs. Cooney's study also contained a number of recommendations on production techniques that were used extensively in the series. She envisioned using puppets, and they came to play a major role. She mentioned using animation to teach letters and numbers, and this technique was used often. She suggested the device of showing four objects on the screen, three of them similar and the fourth not, and asking the child which thing was not like the others; this method of instruction appeared in several forms on the series. (p. 19)

Cooney's recommendation to incorporate puppets into the show was a key element to the overall appeal of Sesame Street. The use of these imaginary puppet characters generated interest in the child-centered audience and led to more screen time and the introduction of puppets as main characters as the series progressed. I have always been fascinated by puppet performances and I learned that art and craft of making various types of puppets such as marionettes and hand puppets. 
The Phoenix Centre for Children and Families (PCCF) is a non-profit organization of child psychologists and social workers which provides services to families in Renfrew County (Ontario). Psychologists and social workers at the PCCF saw the immense value in the use of puppets not only as a means of gaining the trust of the children with whom they worked, but also as a method of getting the children to open up and discuss personal problems. Seizing this potential in using puppetry as a teaching tool, the PCCF developed a puppet program entitled Friends and Neighbours (F.A.N.) Club to be used in elementary schools to educate students on a variety of issues relevant to them (i.e.: bullying, drug abuse, racism etc.).

In 1995, The Phoenix Centre for Children and Families employed me to develop and design 18 puppets that were intended to represent children of diverse ethnic backgrounds. Throughout the development stage, I worked closely with the psychologists and puppeteers and attended many elementary school puppet performances, to gauge audience reaction to a variety of puppet designs. What truly amazed me was how children in the audience responded to the puppet characters. The children treated the characters as their peers, asking the puppets personal questions even though the puppeteers were in full view of the audience throughout the performance.

Another children's television production I worked which had an all-puppet cast of characters was the children's television series Groundling Marsh. This primarily entertainment-based series was well received by the target audience of children aged 6 to 8. However, while working on the set of Groundling Marsh, I observed several production issues that arose as a result of using puppets for a television series. The main 
problem with the puppet-based production concerned the complexities and high costs associated with set design and construction. This issue has been somewhat relieved more recently through the use of green-screen techniques in which the sets and/or background can be added in post-production. A second and more serious problem concerns the limited puppet/puppeteer mobility that resulted in localized puppet action on specific areas of the set. Conversely, the use of computer animation provides the ability of incorporating imaginary characters into a children's program without the high cost associated with set design; while simultaneously eliminating mobility issues of the characters, typically associated with hand puppets.

\section{Computer Animation in Education}

I have worked as a grade-school teacher for several years, focusing on the intermediate grades (grades 6 to 8). I have found the most difficult aspect of teaching involves motivating the students and maintaining student interest throughout a lesson. My passion for animation led to a diploma in computer animation and post-production at the International Academy of Art and Design. One of the unique qualities of animation is its ability to capture the attention of young children. The Art Collector (Bohart, 2004) is an animated short intended to teach grade 6,7 and 8 students about the surrealist style of visual art through an engaging narrative. The narrative centers around an imaginary character named Gunar who falls out of a surrealist painting and into an art gallery. Gunar provides the audience with a guided tour of three surrealist paintings while a narrative describes and explains what this style of art is trying to convey to the viewer. 
Animated cartoon characters provide a level of imagination and fantasy that can match the creative imagination of young children. The captivating power of animation on children has long been realized by the entertainment industry, however its use as an educational medium and tool for children has not been as widespread. One research study which does explore the potential of using 3-D animation in education is described in Yoomi Choi Ju and Lauren Cifuentes' article, Children Learning from Artfully Designed, Three-dimensional Computer Animation (2002). Choi Ju and Cifuentis examine the effectiveness of incorporating artfully designed 3-D computer-generated animation to enhance a child's learning. Choi Ju and Cifuentis explore two central questions in this research inquiry: "Do artfully designed 3-D computer-generated video stories enhance learning or are such entertaining works a distraction from learning?" And, "Do children attend to the content of artfully designed video or are they merely entertained" (p. 46).

Choi Ju and Cifuentis conducted a research study of 110 first grade students in two elementary schools. For this research study, students were given a pre-test to determine prior knowledge and ability to recognize the primary colours including the ability to mix colours to create complementary colours. Students then watched a computer-animated video that demonstrated colour theory through a narrative storyline. After the video was shown, researchers administered a post-test to measure whether the students' ability to recognize and mix colours improved after being subjected to the video.

The pre-test and post-test consisted of having the students choose one of six coloured markers to accurately colour in a circle that corresponded to one of six questions posed by the researchers. The test questions were as follows: 
1. Given a choice of six colours, identify the colour red by using the right marker to colour in a circle.

2. Given a choice of six colours, identify the colour blue by using the right marker to colour in a circle.

3. Given a choice of six colours, identify the colour yellow by using the right marker to colour in a circle.

4. Given a choice of six colours, identify the colour produced by mixing red and blue by using the right marker to colour in a circle.

5. Given a choice of six colours, identify the colour produced by mixing red and yellow by using the right marker to colour in a circle.

6. Given a choice of six colours, identify the colour produced by mixing yellow and blue by using the right marker to colour in a circle. (Choi Ju \& Cifuentes, 2002, p. 46)

The results of the pre-test indicated that $100 \%$ of the students correctly answered question one; $99 \%$ of the students correctly answered question two; $98 \%$ answered question three correctly; $67 \%$ answered question four correctly; $59 \%$ answered question five correctly and $55 \%$ of the students answered question six correctly. After watching the 3-D computer animated video, students showed a significant improvement in their overall ability to recognize the primary colours as well as their ability to mix complementary colours. The results of the post-test indicated that $100 \%$ of the students answered questions one, two and three correctly, while $98 \%$ answered questions four and six correctly and $97 \%$ of the students answered question five correctly. Choi Ju and 
Cifuentes' research inquiry concluded that CG imagery and animation can enhance learning (p. 46). One area of the study that was not explored was the long-term versus short-term memory retention of students who learned colour mixing through the aid of the video. It would be interesting to compare traditional methods of teaching versus the use of computer generated imagery in learning to see whether CG imagery is actually a more effective teaching tool than traditional classroom education.

In the second study, O'Neill (2000) explored the effect of computer-generated animation on the learning process of secondary school students. More specifically, the research investigated whether grade 12 science students benefited from incorporating computer-animated sequences into a biology unit on Photosynthesis. The research question posed by O'Neill' was: Can simple, user-friendly, highly graphical, computergenerated animations bring difficult information to life and, as a result, put difficult information within the reach of all learning abilities? Findings from this study indicate that incorporating computer-generated animation in a high school science lesson enhanced the students' ability to recall facts from the unit on photosynthesis as a whole. Of particular note, O'Neill found that students with lower grades seemed to benefit the most from watching the computer animations. O'Neill states:

... a significant correlation was obtained for the multimedia group between the amount of improvement of each student as calculated by the difference between the predicted and actual grades, clearly signifying a relationship between student improvement and student ability. In other words, the lower the grades, the greater the improvement. For the control 
group no significant correlation was evident. It is important to qualify the nature of this improvement. Generally, lower ability students may be expected to improve more than higher ability students because the lower ability students have more scope for improvement. ${ }^{5}$

O'Neill's study is further evidence to support the use of computer-generated media as an educational tool.

Sesame Street has also been instrumental in proving that through careful planning, combined with a talented team of media professionals as well as an adequate source of financing, the medium of television can be harnessed as an educational resource for children. I have used several examples to illustrate how computer generated imagery can be successfully incorporated into an educational environment as well.

\section{Photorealistic Graphics as a Means to Understand Art}

I was fortunate to have seen the Special Interest Group in Graphics (SIGGRAPH) Computer Animation Festival in 2002, which contained a five-minute animation on John Wallace's CGI recreation of Johannes Vermeer's painting The Music Lesson. The animation was more than simply a showcase for Wallace's computer graphic, it provided the audience with an in-depth understanding of how Vermeer planned out and recreated the linear perspective, as well as the lighting for his painting. The three-dimensional CGI recreation enabled the "virtual" camera (and therefore the audience) to move within and

\footnotetext{
${ }^{s}$ http://www.esatclear.ie/ fergalmj/meta/methodology2.htm Retrieved January 10, 2008.
} 
through the recreation of the room in The Music Lesson. The combination of the moving camera, a clear narrative audio track, and animated "lines" illustrating the artist's perspective, all helped to provide a level of understanding that traditional art instruction would be unable to match.

Recent advancements in computer hardware and software technology, have enabled media artists to develop photorealistic animated films. The photorealistic quality of the animation relies on the rendering engine of computer software. The strength of the computer software that is used to create realistic images in-turn, relies on complex mathematical algorithms to determine how "virtual light and shadows" would realistically fall on a computer-generated scene. However, computer programs still have difficulty re-creating the images the brain perceives autonomously. During sleep, the human brain can effortlessly combine startlingly realistic images with completely disconnected or unrealistic scenarios. These same scenes can be achieved through computer animation, however this comes at considerable time and expense.

In their book, Remediation: Understanding New Media, Bolter and Grusin (2000) provide a detailed account as well as the methodology and philosophy of the photorealist movement in painting, photography and most recently, through the use of computer graphics. As the title of their book suggests, the authors examine remediation through various forms of new media, with a particular emphasis on computer-generated imagery. 
Bolter and Grusin (2000) explore the potential of using photorealistic computer graphics in art. In an explanation of this emerging art form, Bolter and Grusin write: Photorealistic computer graphics seeks to create a space that is purified of all references to itself as a medium and to other media, and yet it never seems to be able to maintain that purity. Instead, it must appeal to us through the traditions of linear-perspective painting and photography. ( $\mathrm{p}$. 115)

Bolter and Grusin explain that computer animation artists are attempting to create a niche for computer-generated imagery as an art form that is unique from any other. In order to achieve this, computer animation artists must rely on the fundamental principles of art theory, developed for painting, photography and film.

A central focus of Bolter and Grusin's chapter examines the potential of using computer graphics as an educational tool to better understand the vision of master painter Johannes Vermeer. Bolter and Grusin compare a Vermeer painting entitled The Music Lesson with two 'remediations' of this work. The first remediation of The Music Lesson was recreated by art critic and scholar Philip Steadman as a physical scale model to study Vermeer's mastery of linear perspective. The second recreation of The Music Lesson is a computer-generated image created by John Wallace, a professor in the Program of Computer Graphics at Cornell University. Wallace chose to depict this particular Vermeer painting because the painting is considered to be a fine imitation of the real. Another reason the Vermeer painting was chosen by Wallace was that he wanted to 
compare the ability of computer graphics to produce lighting and shading to that of a master painter. Wallace used his reproduction to demonstrate that the quality of a computer-generated image (CGI) is approaching photorealistic painting.

Both the physical model and the computer graphic share a commonality as representations. Steadman's physical model and Wallace's computer graphic attempt to illustrate the Vermeer painting by making the medium each uses as transparent as possible to the viewer. However, as Bolter and Grusin (2000) write: "...both AND end up being hypermediated and so draw the audience's attention to the medium they sought to cancel "(p. 117). The viewer of these representations becomes more interested in the model and ends up focusing on the media that created it. While the uses of these models are excellent tools for instruction, it is impossible to make the media transparent to the audience.

In addition, a documentary on Vermeer's paintings, entitled Vermeer: Master of Light (Karkora, 2001), contains a ten-minute computer-generated animated sequence of the Vermeer painting The Music Lesson, similar to the recreation of Wallace's computergenerated graphic. The animation found in the documentary provides the viewer with an in-depth understanding of how Vermeer planned out and recreated the linear perspective, as well as the incredibly realistic lighting and shadows found in The Music Lesson. Being a three-dimensional computer-generated sequence, the camera (and therefore the audience) is able to move within and through the recreation of Vermeer's studio in The Music Lesson painting. The combination of the moving camera, a clear narrative audio 
track and the effective use of animated arrows and lines were ingeniously combined to provide a level of understanding that traditional art instruction would be unable to match.

Bolter and Grusin (2000) use the Vermeer reproductions to demonstrate how photorealistic computer graphics are being used to further reproduce earlier reproductions, such as recreating a photograph or a painting. After viewing the animation of Wallace's computer graphic, it becomes evident that the true potential of computer generated imagery and animation lies in its use as an educational tool. Computer animation can combine video, audio, special effects, narration, and printed word to engage all of the senses of the viewer/learner.

All of these examples have been provided to illustrate the ways in which CGI can be used as an educational tool. The positive results indicated in the research studies of Choi $\mathrm{Ju}$ and Cifuentes (2002), and O'Neill (2000), together with the rapid advancement of technology use in Ontario classrooms, suggest to me that my research project incorporating animation into an arts-based curriculum is timely. In short, by drawing on educational policy and theory, my research project creates animation to be used as an artful alternative cognitive tool for teaching. 


\section{CHAPTER IV: THE ART COLLECTOR: ANIMATION AND THE ONTARIO CURRICULUM}

My interest in educational children's media led to my development of the educational resource entitled The Art Collector. This resource is intended to be used to educate children about the surrealist style of visual art using Macromedia's Flash MX computer animation software. In this chapter, I provide a full script of my animated short film that accompanies a CD copy of the full animation (see Appendix A). The intention of including the script and $\mathrm{CD}$ is to provide the reader with an understanding of the ways in which the final animated film differs from the original script as a progression from the original concept to a final animated production. Finally, I provide an example of how The Ontario Curriculum, Grades 1-8: The Arts, 1998, can be applied to The Art Collector as a resource for elementary teachers.

\section{The Art Collector Animation Script}

\section{"THE ART COLLECTOR"}

FADE IN:

ON ART GALLERY EXT. - NIGHT 
STATIC SHOT OE THE GALLERY. A closed sign hangs in the lobby window. THE SEX OE HOWLING WIND AND A BARKING DOG IN THE DISTANCE.

MDS INSIDE ART GALIERY. SURREAIISM EXHIBIT - NIGHT

Inside a room of the surrealism exhibit, several large paintings hang on the wall. The place is empty and the SEX OF A CLOCK TICKING breaks the silence. High on a wall, a clock shows 11:53pm indicating the gallery is closed. In the centre of the room lay several bizarre sculptures and a small bench seat.

\section{NARRATOR}

The paintings in this room are part of a surrealist exhibit. Surrealism is a style of art that began in Erance in 1924. With surrealism, the artist is trying to visually represent the content of our subconscious, our dreams. We 


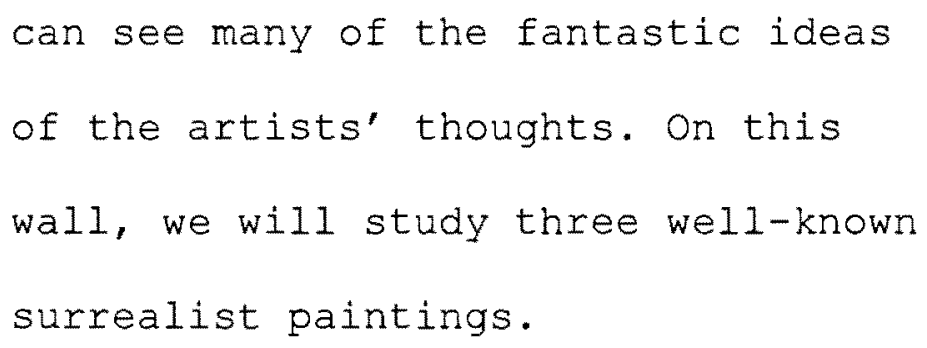

MCU PAINTINGS ON THE WALL

CAMERA SLOWLY PANS EROM LEET TO RIGHT along three large paintings. Camera moves past the first painting...

\author{
NARRATOR \\ This painting is called the \\ Persistence of Memory by Salvador \\ Dali.
}


MCU PAINTINGS ON THE WALL

CAMERA SLOWLY PANS FROM LEFT TO RIGHT Camera moves past the second painting...

\section{NARRATOR}

This is called surrealism and Painting by Max Ernst.

MCU PAINTINGS ON THE WALL

An odd little creature named GUNAR stands in the foreground of this painting. He is tall and thin, with a body that resembles an ostrich and the head of an aardvark. GUNAR is purple except for his orange trunk and feet. The inquisitive eyes of GUNAR blink and follow as the CAMERA PANS to the third painting.

NARRATOR

This painting is called The False Mirror by René Magritte. 
MCU PAINTINGS ON THE WALL

THE CAMERA QUICKLY PANS BACK to the middle painting but the strange creature is no longer there. GUNAR pokes its head into the frame and walks into the painting's frame from camera right. GUNAR stops when he spots the camera.

\author{
NARRATOR \\ This is Gunar. Gunar is a curious \\ little creature who lives inside the \\ worlds of the artists' paintings. \\ Every night when the gallery is \\ closed and the people have gone home, \\ Gunar wanders through the gallery \\ exploring the paintings.
}

MCU PAINTINGS ON THE WALL 
He pauses and blinks as if deep in thought. GUNAR steps forward and then leans in way forward for a closer look. He loses his balance, falling out of the painting and out of frame.

MCU ANGLE ON GUNAR

GUNAR gets up looking confused and embarrassed. GUNAR walks over to the Salvador Dali painting. Gunar turns to face the camera with a bewildered look and then turns back to the painting.

NARRATOR

Salvador Dali painted the Persistence of Memory in 1931. The realistic landscape, hard rocks and strange blocks are contrasted with soft, dripping watches. In the center of the painting is a soft selfportrait of the artist's head. Salvador Dali uses the soft watch as 


\author{
a metaphor for human's obsession with \\ time, and the idea that time is set \\ against us.
}

MCU ANGLE ON THE PERSISTENCE OF MEMORY

GUNAR climbs into the painting. His weight causes the painting to tilt and the clock at the bottom left slides/pours out of the painting and onto the floor. Gunar quickly walks out of the Dali painting and into the Ernst painting.

\title{
NARRATOR
}

Max Ernst created Surrealism and Painting in 1935. Strange, multicolored birds sit in a nest in the centre of the painting. The long necks of these birds transform into elongated semihuman arms and legs. The neck of one bird emerges into the arm and hand of the artist, to paint 


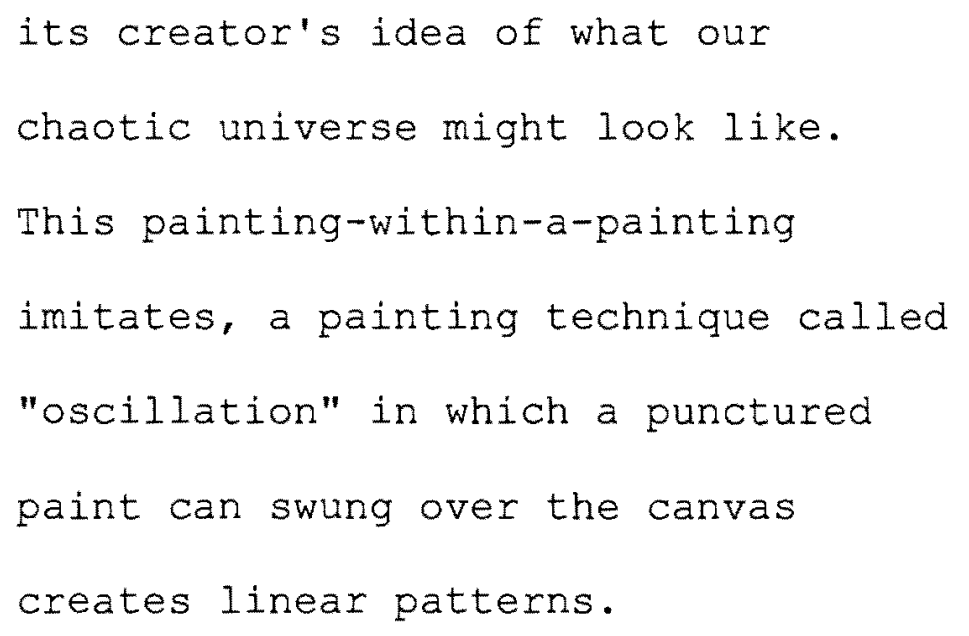

MCU ANGLE ON PAINTING AND SURREALISM

GUNAR continues through this painting and accidentally knocks the painting off the easel, sending it crashing to the floor of the gallery. Once again, Gunar is embarrassed by his actions and hurries out of the Ernst painting and into the Magritte painting. GUNAR finds himself standing inside a giant eye. Behind him is a brilliant blue sky containing white puffy clouds. GUNAR stops walking directly behind a large black pupil which blocks his view of the gallery. 


\begin{abstract}
NARRATOR
René Magritte painted The False

Mirror in 1935. Our eyes provide us

with the ability to see the world

around us and to experience reality.

It has been said that the eye is the

mirror of the soul. In this

painting, the artist has replaced

the iris of the eye with a blue sky.

The eye has been transformed from a

mirror into a vast open space.
\end{abstract}

MCU ANGLE ON THE EALSE MIRROR

GUNAR tries to look over the black pupil, however he bumps it with his nose, sending it bouncing out of the painting like a rubber ball.

\title{
NARRATOR
}

Well that about wraps it up for what goes on in the middle of the night at the art gallery. Tune in 


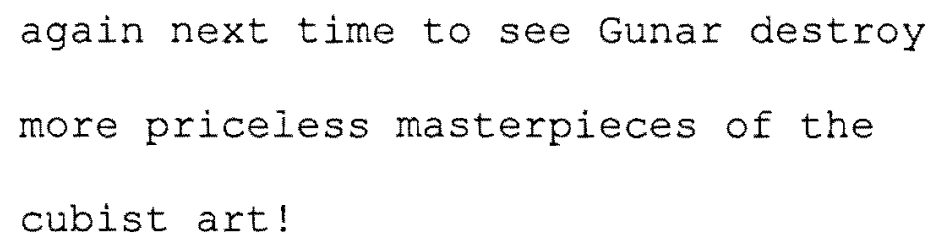

MCU GUNAR SURREALIST EXHIBIT ROOM - NIGHT

PAN OUT to reveal the surrealist exhibit room in a complete state of disarray. GUNAR blinks sheepishly from Max Ernst's. giant eye.

FADE OUT

\section{The Art Collector: Process and Development}

The premise for The Art Collector is based on the concept that a painting can be thought of as a window that looks into the world envisioned by an artist. The central character of The Art collector is Gunar, an imaginary creature that lives inside the artists' worlds. Gunar is able to move between the "real world" of the art gallery, and the worlds of the paintings. For this project, I chose not to have Gunar speak, but I opted instead to use an accompanying voice-over narration. My rationale for this was that Gunar's humourous actions would be able to hold the attention of a young audience while the narration would be able to give the audience a better understanding of the paintings and artists. Gunar becomes a guide to transition the audience through the on the journey through three surrealist paintings. 
The storyline involves three scenarios whereby Gunar in the late hours of the night at an Art Gallery explores the inner worlds of the paintings as envisioned and portrayed by the artists: Salvador Dali, René Magritte and Max Ernst. The purpose of The Art Collector project is to provide a practical educational tool that incorporates computer animation technology with art theory, to educate about art theory and art history in a unique way through paintings from these three different surrealist artists.

In the first scenario, Gunar climbs into Salvador Dali's painting, "Persistence of Memory." As he climbs into the painting, his weight tips the painting and one of the "soft" watches in the painting "pours" out onto the gallery floor.

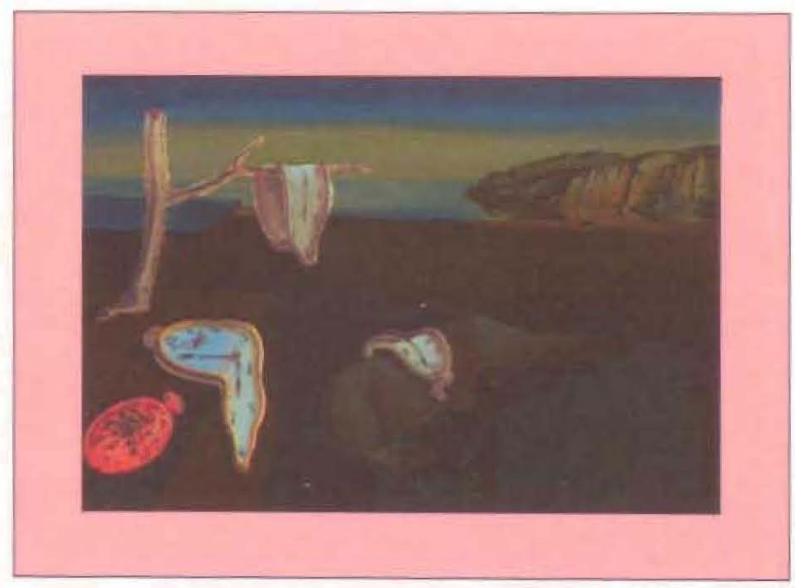

Figure 1: The Art Collector: "Persistence of Memory 1" 


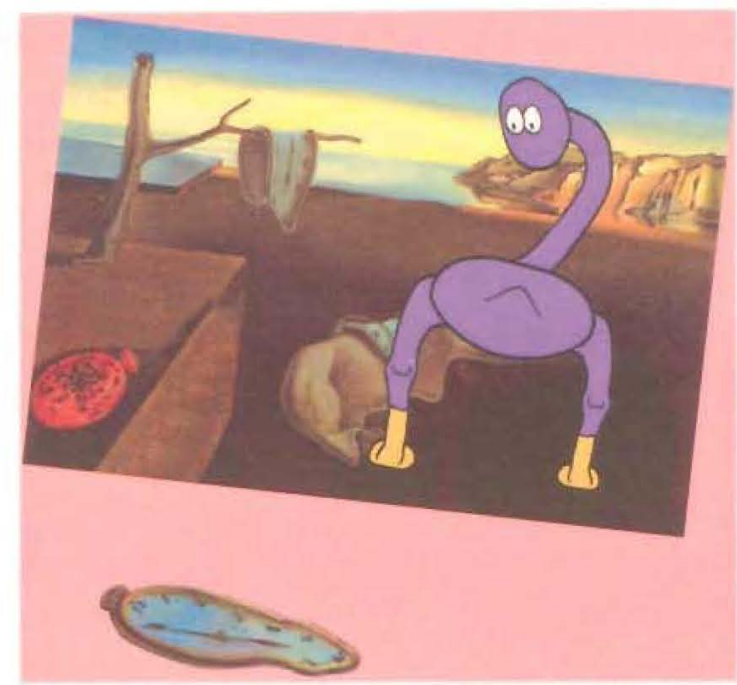

Figure 2: The Art Collector: "Persistence of Memory 2"

In the second scenario, Gunar enters Max Ernst's painting "Surrealism and Painting" and walks behind the white birdlike creature in the centre of the painting.

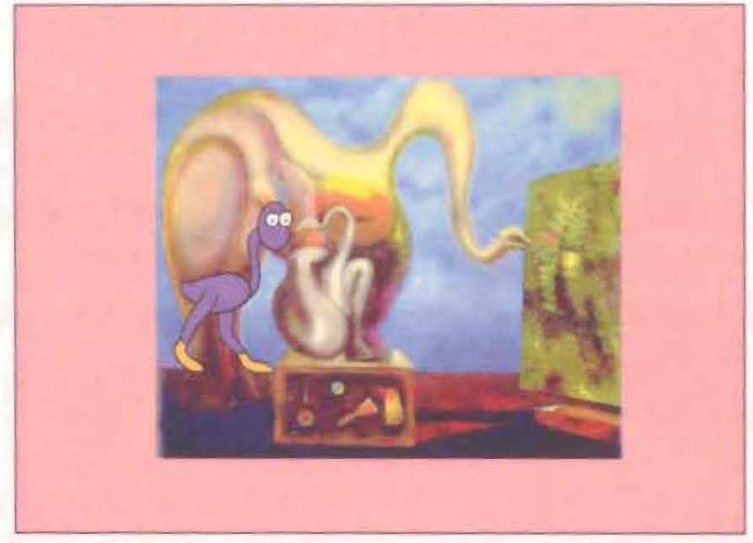

Figure 3: The Art Collector: "Surrealism and Painting 1"

The white bird reminded me of a porcelain vase, so I had Gunar accidentally knock over the sculpture which subsequently shatters as it falls out of the painting and hits the floor. This short, humorous scene keeps the audience's attention while the voice-over 
describes the elements within the painting and provides some brief background information on the artist Max Ernst.

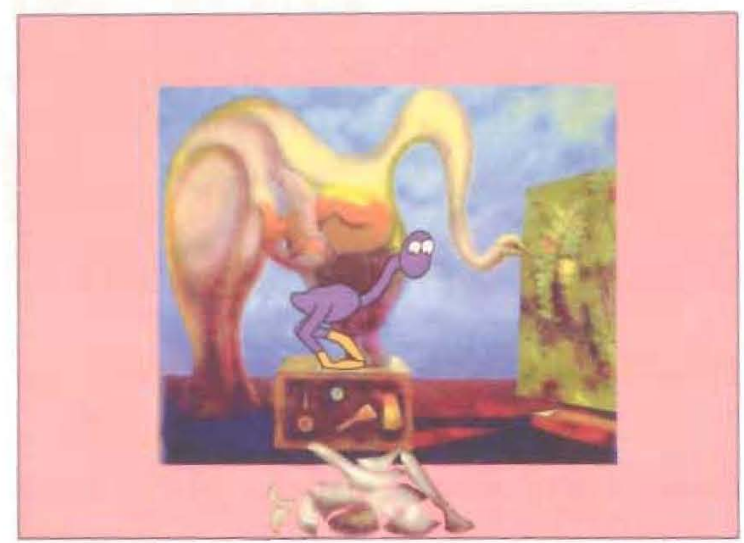

Figure 4: The Art Collector: "Surrealism and Painting 2"

The third scene has Gunar interacting with René Magritte's painting "The False Mirror". This painting is essentially an extreme close-up of a realistic human eye. The only surreal element of this painting is that Magritte has replaced the iris of the eye with a cloud-filled blue sky. The pupil appears to be suspended in the sky. I find it interesting that while the eyelid (and more specifically the tear duct) has been painted with realistic highlights and shadows, the pupil is devoid of any highlight, which is typically found when a light source hits the eye. 


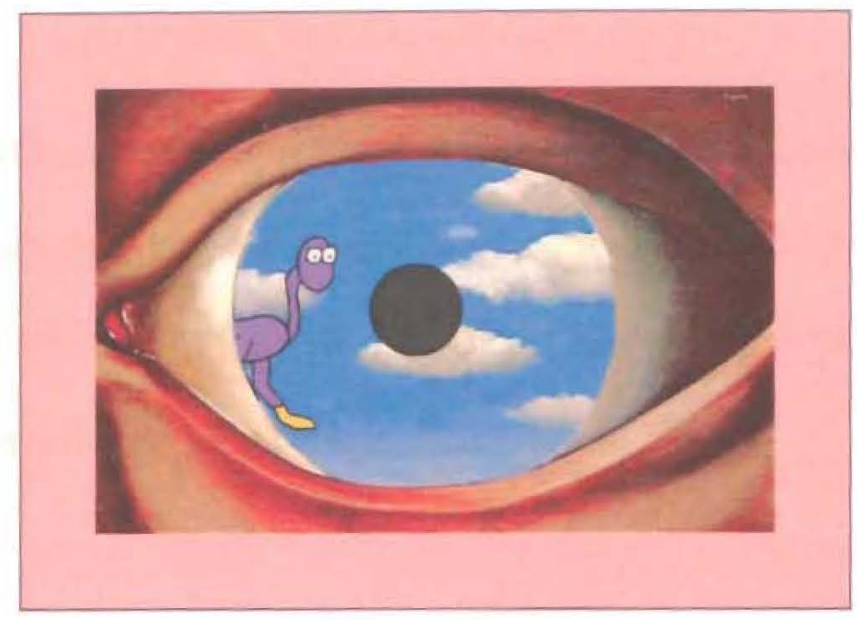

Figure 5: The Art Collector: "The False Mirror 1"

The pupil is reminiscent of a child's ball, so once Gunar kicks the ball, it bounces out of the painting and out of the frame. While the audience is watching the humorous scene unfold, the voice-over explains the symbolism Margritte uses in this painting.

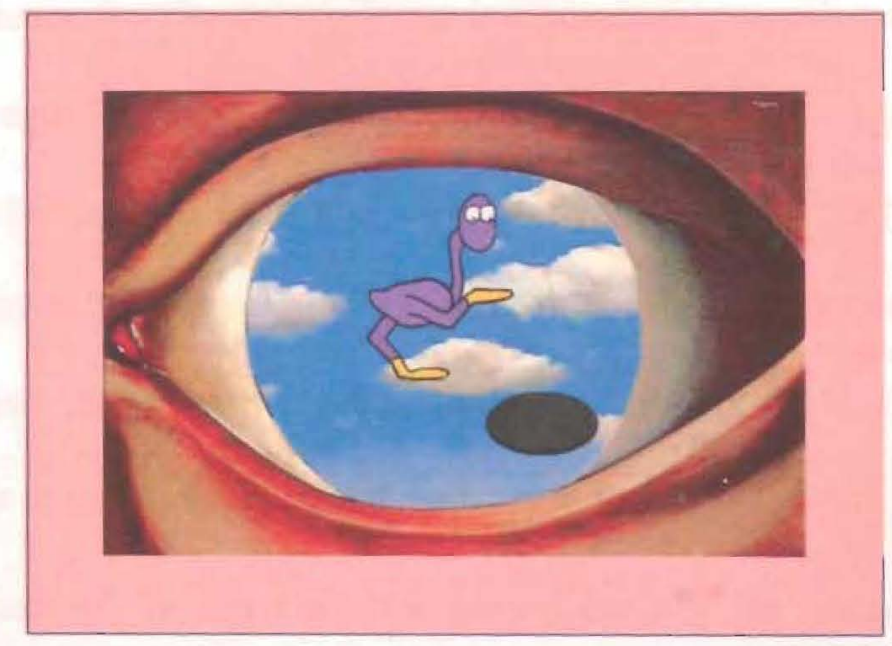

Figure 6: The Art Collector: "The False Mirror 2" 


\section{Surrealism and The Art Collector Project}

Surrealism was chosen as the preferred style of visual art to present in this animated video project for several reasons. The surrealist movement attempted to explore the subconscious mind in a visual way. In their book, Artworks for Elementary Teachers, Herberholtz and Herberholtz (1994) describe surrealism:

In a fantasy or surrealistic work, we see that the artist delved into the world of dreams and the subconscious or fanciful unreal world of the imagination. ...In these artworks, the emphasis is on the imagination and the world of the subconscious. The artist often depicts objects in a very realistic manner but makes unusual connections and relationships. (pp. $114-115)$

The target audience for The Art Collector is students from grades 6,7 and 8, between 11 to 13 years of age. Students at this age/grade level are beginning to represent realism (including depth perception, light and shadow, textures and patterns as well as the elements of design) in their visual artwork. In addition, there is a tendency to incorporate fantasy imagery and imaginary subject matter in the artwork of 11-13 year olds, which parallels the ideals of the surrealist movement.

The development of The Art Collector project can also be used as a case study for exploring how the final style of the animation was affected by the software technology I chose to create it with. I initially planned to create The Art Collector using the 3D 
computer animation software Softimage. Figure 7 shows the original 3-D image of Gunar, the main character.

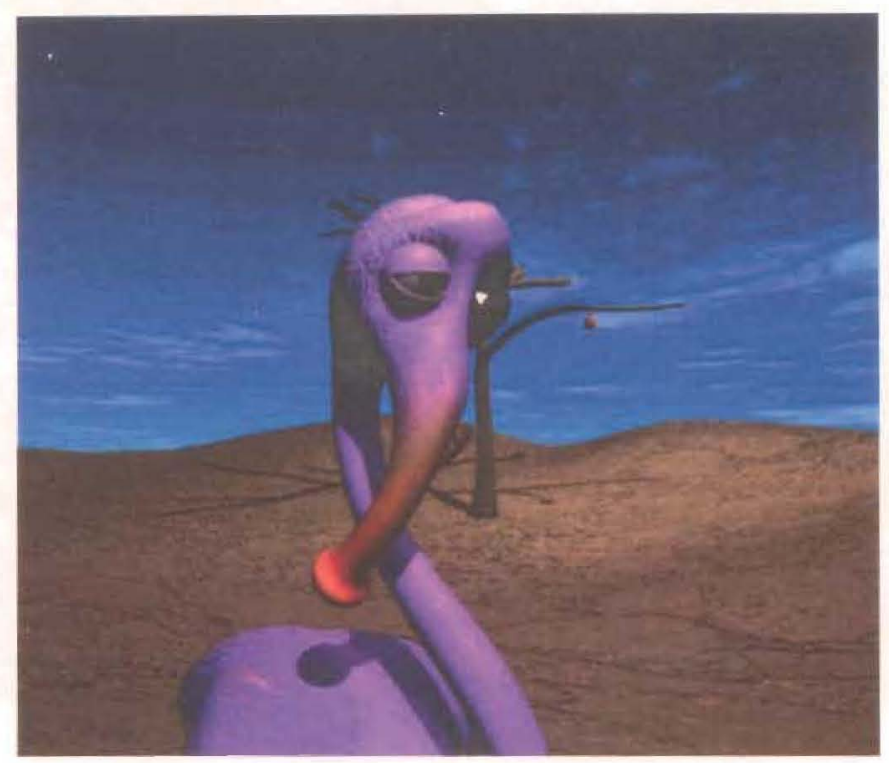

Figure 7: The Art Collector in 3-D computer animation software

Completing the animated short in Softimage would have created a more realistic approach as the character and setting would have had realistic textures and shadows. Due to the length of time required to produce a five-minute animation using $3 \mathrm{D}$ animation software, I opted instead to use Flash animation software. This decision resulted in a much more cartoon-like two-dimensional feel for the final production as featured in Figure 8 . 


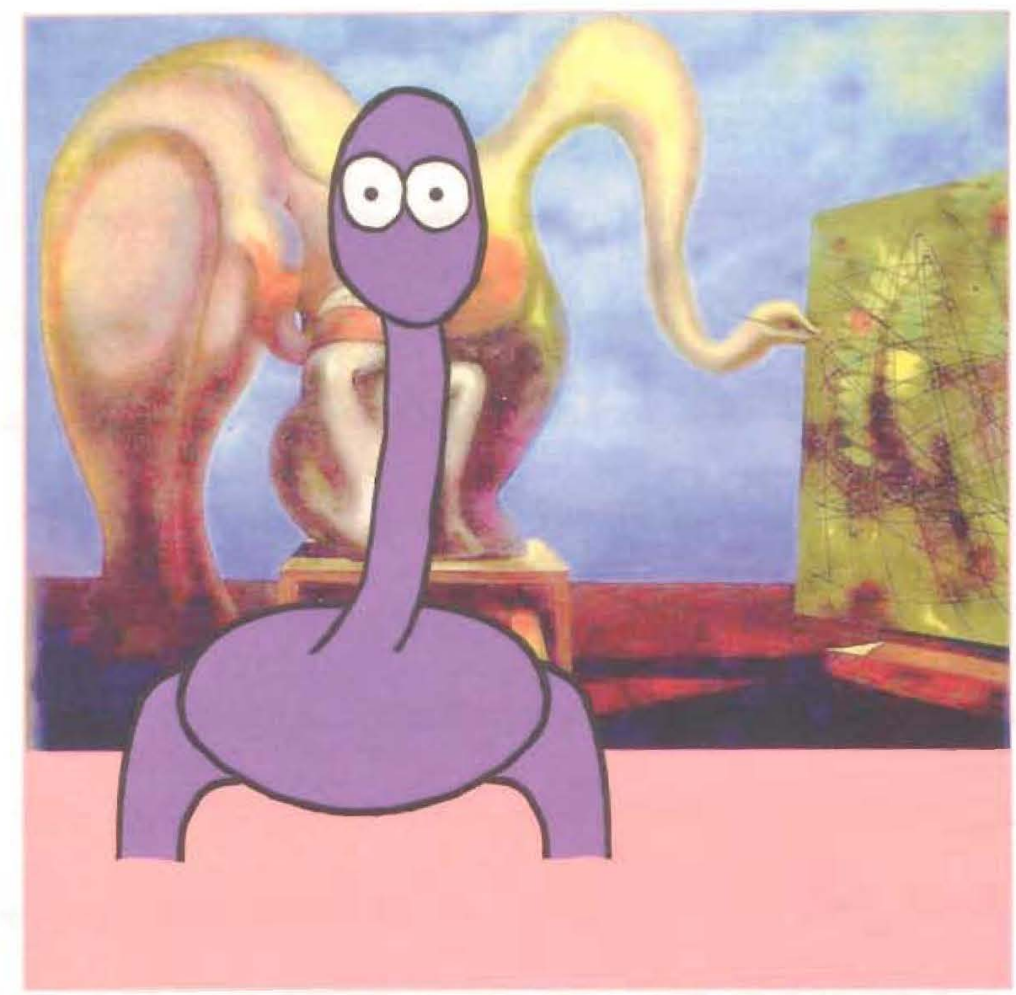

Figure 8: The Art Collector in 2-D Animation

The 2-D feel is most often associated with humour, so once I decided on the software I planned to use, I revised the script to add more humorous elements. The Art Collector is an example of how my choice of software, or technology, played an important role in the style, look, overall feel and even the content of the final animation. My script and 2-D animated short film is an example of how technology influences forms of art.

\section{A Visual Art Unit: Understanding Surrealism}

My research project contains three main components. The central part of the project was the actual animated short, The Art Collector. The second section was my analysis of and argument in favour of using computer animation software as a tool to enhance 
learning in the intermediate-level classroom. In this section, I also explained the planning and development of The Art Collector project. The final section provides an overview of how The Art Collector could be incorporated into a grade 8 Ontario curriculum for artsbased instruction. The Art Collector is intended to be used several times throughout the unit. The proposed unit balances several lessons in the theory and principles of surrealism with practical, hands-on experimentation in surrealistic-style painting and drawing.

The first lesson of the unit "Understanding Surrealism" explores the surrealist style of painting through a class discussion. After a brief introduction to the new unit, the teacher would establish what students already know about this style of art, through a short pretest. The teacher would then show The Art Collector to the class. The Art Collector is used here as a motivator or "hook" to get students interested in wanting to learn more about surrealism.

The teacher would generate a group discussion about terminology used in the unit. On chart paper, the instructor would get the class to come up with definitions of the following terms: artistic style; reality; surreal/surrealism/surrealist; expressive; mood; automatism. The discussion would also include specific questions about the events students saw in the animated short. The instructor might ask if students can remember any of the artists mentioned in the animation. Several questions the teacher might ask are: "Can you name any other surrealist artists?" "What was surreal about The Art Collector story?" "Why do you think these artists painted in a surreal style?" These are just a few examples of how The Art Collector could be used to generate interest and discussion of surrealism. At the end of the first lesson, students would be assigned a group to research 
and present information on a surrealist artist. The groups would be able to choose a surrealist painting and artist from a predetermined list. In the next lesson, students would be expected to conduct research at the library or computer lab, on their chosen artist and painting.

The second lesson of this unit explores the surrealist artists and their paintings. This lesson would be conducted in the library or computer lab. The teacher would begin by providing each group with a short list of questions each group must answer concerning the artist and painting chosen by their group. The instructor would then show the group The Art Collector again. This time however, the animated short would be used as an example to illustrate how students would be able to answer questions about their chosen painting and artist. The students would be able to use the rest of the class to conduct research on their painting. The objective for this lesson would be for the groups to answer the questions provided, in a short, word-processed report. The groups would be expected to finish this assignment outside of class time.

In the third lesson of the 'Understanding Surrealism' unit, students would provide short group presentations of the paintings and artists they chose to research. Required resources for this lesson include: a computer, a data projector and digital pictures of the surrealist paintings the students will present. As each group comes up to provide the answers to questions about their painting/artist (given out in lesson two), the teacher would project a digital version of the painting so the group can refer to specific parts of the painting. After all the groups have presented, the teacher would recapitulate the main points of surrealism. The fourth and fifth lessons would involve the students exploring 
surrealism through their own drawings and paintings. Appendix B provides an overview of the unit "Understanding Surrealism" and Appendix C is a sample lesson plan from the unit.

In this major research project, I learned that by looking at various forms of art such as painting, film, and photography in addition to animation, technology clearly played and continues to play a large role in the development of new forms of art, as well as influencing artistic styles. I also learned that within the last century however advances in technology have become a major factor in bringing about change in both artistic style, as well as in our thinking of what can be "considered" art. New forms of technology such as photography, film, video, computers, computer graphics, the Internet and various forms of digital media have all influenced the way we create, understand and view art.

I began with a brief history of the computer animation software industry in Canada. I investigated the influence computer technology has had on the animation industry, as well as the role animation software plays in the look or style of animated films. I also examined the impact that three-dimensional computer animation has had on traditional animated films. I was concerned with the ways in which computer animation software has been largely responsible for a shift away from the wide variety of "cartoony" artistic styles of the 1960's to the current trend of hyper-realistic three-dimensional animation in more recent films.

I examined the educational television program for children, Sesame Street, in order to understand what makes this show so unique. I provided an historical account of regulatory policy of children's television programming and objectives as well as the 
implementation of the United States government's Children's Television Act (CTA) of 1990. I reviewed the results of two research studies to illustrate how effective the integration of three-dimensional computer generated imagery (CGI) can be used as an alternate mode of learning, within the classroom environment (Choi Ju \& Cifuentes, 2002; O'Neill, 2000). The results of these research studies prompted me to develop my own educational animated film titled, The Art Collector (Bohart, 2004).

My major research project involved the development of an animation short titled The Art Collector (Bohart, 2004), that explores the surrealistic art movement through an engaging storyline. The Art Collector was the major component of this project that served as a concrete example of the ways in which forms of new media can be used to enhance an educational unit. I examined empirical data obtained from case studies (Choi Ju \& Cifuentes, 2002 and O'Neill, 2000) that explored how technology, such as animation, can be used successfully as a teaching aid in the classroom.

Finally, I outlined the process of developing my animated short film project, The Art Collector, and provided an example of the ways in which this animation short could be incorporated into the existing intermediate public school curriculum through a lesson/unit plan. The purpose of The Art Collector project was twofold: a) to provide a practical educational tool that incorporates computer animation technology with art theory, and b) to educate about art theory and art history in a unique way through paintings from three different surrealist artists: Salvador Dali, René Magritte and Max Ernst. I provided some background as to how this animation project came to be, including the development of the script, the main character, and the animation itself. I illustrated how the final version 
of The Art Collector has differed slightly from the original concept. Drawing upon the research results of Choi Ju \& Cifuentes, 2002 and O'Neill, 2000, I deduced that animation can be used successfully as an education tool to motivate student learning.

Future considerations for this research include inspiring teachers and students to develop their own animated sequences to introduce complex ideas and concepts using computer animation software. Therefore, the Art Collector project is also intended to act as an example of how teachers and students might develop their own animated sequences. A teacher might work with several students to create a sequence on geometry. Although Flash MX can handle complex character animation, the intuitive nature of the software enables novices to create simple animation in a relatively short amount of time.

Flash MX also allows for "hotspots" to be added within an animation. The viewer can click on these hotspots to access more information about the subject, or to link to a different animation sequence. Empowering the viewer with these hotspots gives them more choice for interactivity. Media websites such as www.googlevideo.com, www.youtube.com and more recently, www.teachertube.com provide a free and easy way to disseminate and share their animation or video presentations with others. My future plan to extend this project is to develop several other animated sequences based on the same character, Gunar. New sequences would explore other styles of art such as impressionism, cubism and romanticism. 


\section{References}

Aufderheide, P. (1994). Why kids hate educational TV. Media Studies Journal, 8(4).

Bohart, A. (2004). The art collector: Unpublished Animation Script.

Bolter, J. D., \& Grusin, R. (2000). Remediation: Understanding new media. Cambridge: MIT Press.

Choi Ju, Y., \& Cifuentes, L. (2002). Children learning from artfully designed threedimensional computer animation. Informational Technology in Childhood Education Annual, 2002(1), 45-60.

Foldes, P. (1972). The computer and I: From the program notes of the international animation festival in New York. In R. Russet \& C. Starr (Eds.), Experimental animation origins of a new art. New York: Litton Educational Publishing.

Herberholz, D., \& Herberholz, B. (1994). Artworks for elementary teachers. Madison, Wisconsin: Brown \& Benchmark.

Karkora, J. (Writer) (2001). Vermeer: Master of light. Toronto: National Gallery of Art.

Mazurkewich, K. (1999), Cartoon capers: The history of Canadian animators. Toronto: McArthur and Company.

Menache, A. (2000). Understanding motion capture for computer animation and video games. New York: Morgan Kauffmann.

O'Neill, F. (2000). Animation in education. Retrieved January 10, 2008, from http://www.esatclear.ie/ fergalmj/meta/default.htm

The Oxford English Dictionary. (1989). London: Oxford Press. 
Polsky, R. (1974). Getting to Sesame Street: Origins of the Children's Television Workshop. New York: Praeger Publishers.

Postman, N. (1986). Amusing ourselves to death. Toronto: Penguin.

Russett, R., \& Starr, C. (Eds.). (1976). Experimental animation: Origins of a new art. New York: Da Capo Press.

Seuss, D. (1990). How the grinch stole Christmas. New York: Random House.

Walt Disney (Writer) (1937). In W. D. Productions (Producer), Snow White.

Walt Disney (Writer) (1959). In W. D. Productions (Producer), Sleeping Beauty.

Weinstock, N. (1986). Computer animation. Menlo Park, CA: Addison-Wesley Publishing. 
Appendix A

Attached is a CD of a computer generated animated film, The Art Collector.

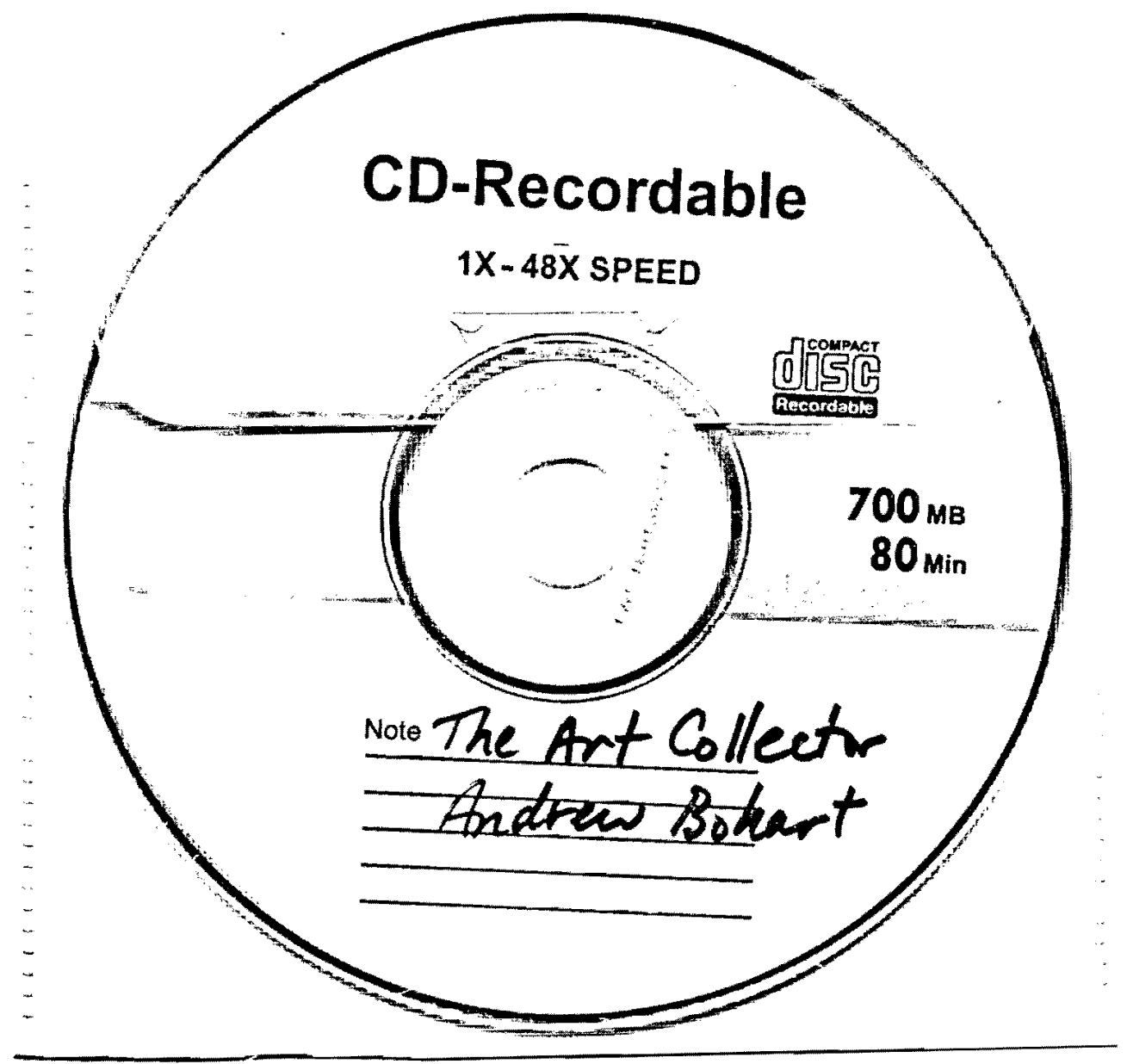




\section{Appendix B}

\section{Unit Plan: The Art Collector}

Topic: Art Theory

Grade Level: 8

Unit Title: Understanding Surrealism

\section{Curriculum expectations:}

By the end of this unit, students should have a good understanding of the surrealist movement of visual art. Students will learn about the history of the movement and will explore the paintings of several surrealist artists including: René Margritte, Salvador Dali and Max Ernst.

\section{Where this fits into larger unit:}

This surrealism unit will be incorporated into a larger unit that explores several different of artistic styles including: impressionism, cubism, and romanticism.

\section{Unit Description:}

The unit Understanding Surrealism aims to provide an understanding and appreciation of surrealism through a combination of art theory, multimedia, and hands-on experimentation in painting and pencil drawing.

\section{Materials:}

- computer,

- data projector and screen,

- digital images of surrealist paintings,

- Chart paper and markers

- Access to a computer lab

- $\quad$ Paint, paper, brushes, pencil crayons

Intro: Motivational Set

View The Art Collector animation 


\section{Lesson Sequence:}

\begin{tabular}{|c|l|l|l|}
\hline Class & \multicolumn{1}{|c|}{ Topic/Content } & Instructional Objectives & Assessment \\
\hline 1 & $\begin{array}{l}\text { Introduction of } \\
\text { surrealism artists } \\
\text { and paintings }\end{array}$ & $\begin{array}{l}\text { - Discussion of surrealism } \\
\text { - Show The Art Collector } \\
\text { - Develop definitions to } \\
\text { surrealism terminology }\end{array}$ & Pre-test on surrealism \\
\hline 2 & $\begin{array}{l}\text { Group research on } \\
\text { surrealist paintings }\end{array}$ & $\begin{array}{l}\text { - Organize students in } \\
\text { groups } \\
\text { - Allow groups to chose a } \\
\text { surrealist painting from a } \\
\text { list. } \\
\text {-Provide groups with a list } \\
\text { of questions to answer } \\
\text { about their chosen painting } \\
\text { - Groups will use the } \\
\text { computer lab and internet } \\
\text { to find the answers to the } \\
\text { question. }\end{array}$ & $\begin{array}{l}\text { Group research and } \\
\text { submission of answers } \\
\text { to surrealism questions. }\end{array}$ \\
\hline 3 & $\begin{array}{l}\text { - Groups present the } \\
\text { answers to the questions on } \\
\text { their painting/artist }\end{array}$ & $\begin{array}{l}\text { Graluation of group } \\
\text { presentations }\end{array}$ \\
\hline $4 \& 5$ & $\begin{array}{l}\text { Grovide students with } \\
\text { time and guidance to } \\
\text { experiment with surrealism } \\
\text { in their own drawing and } \\
\text { painting } \\
\text { painting in the } \\
\text { surrealist style }\end{array}$ & $\begin{array}{l}\text { Evaluation rubric for } \\
\text { students' artwork }\end{array}$ & Post-test on surrealism \\
\hline
\end{tabular}

\section{Closure and Check for understanding:}

- pre and post tests on surrealism

- Creating works of art in the surrealist style using mixed media

- Presentations on Surrealist paintings and artists

\section{Special Needs - accommodation/modification:}

As needed 
APPENDIX C

\section{Unit: Understanding Surrealism Lesson Plan 1: Exploring Surrealist Paintings}

Teacher: Grade: 8

(A.) Specific Expectation(s): Strand: Code:

(B.) Materials and Resources:

- computer $\bullet$ data projector $\bullet$ projector screen $\bullet$ The Art Collector animation $\bullet$ coloured markers

- chart paper and stand $\bullet$ digital photos of surrealist paintings $\bullet$ pencils and drawing paper
(C.) Important Terminology:
(D.) Background Knowledge:
- style - surreal
- surrealism
- expressive
- surrealist
- automatism
- mood
- reality
- Surrealism
- Understanding dreams and what dreams are
- Reality vs. Imaginary
- What is artistic style?

(E.) Motivator: (Exploratory Activity)

- Show The Art Collector (5 minutes). Generate a class discussion.

(F.) Lesson Overview:

1. Briefly introduce the new unit on surrealism.

2. Have the students complete a pre-test to establish what they already know about this style of art.

3. On chart paper, get the class to come up with definitions of the following words:

- Artistic style $\bullet$ reality surreal $\bullet$ surrealism $\bullet$ surrealist $\bullet$ expressive $\bullet \operatorname{mood} \bullet$ automatism

4. After showing The Art Collector to the class, discuss the animated film with them. Explore several questions such as:

- What part of the film might be realistic and what could be considered unrealistic?

- Can you name any other surrealist artists?

- Why do you think these artists painted in a surreal style?

- Which of the paintings did you like about best? Why?

5. Assign students to work in groups of three. Each group will choose a surrealist painting (and corresponding artist) from a pre-determined list. Groups will be assigned a list of questions they are required to answer about their chosen painting.

6. In the next lesson, students will research their painting and artist in the computer lab in order to find the answers to the questions. 


\section{(G.) Evaluation:}

Before showing The Art Collector animation, provide a pre-test on surrealism to test the students current knowledge about surrealism.

Class discussion to establish definitions of terms used in this unit.

\section{(H.) Enrichment:}

Stuaients can use the Internet and library resources to research the biography of another surreal artist and some of their paintings.

\section{(I.) Remediation:}

Provide copies of Salvador Dali's Persistence of Memory and have students describe what they see. Have students redraw the painting.

\section{(J.) Implications for Future Lessons:}

This lesson provides students with a solid overview of what surrealism is. The way the artists and their paintings are presented in The Art Collector can be used as an exemplar for how student groups might present their findings about their chosen artist/painting in a future lesson. The principles and purpose of surrealism explained in this lesson will be instrumental in providing an awareness of this artistic style. Students will use this understanding of surrealism when they paint and draw their own surreal artwork in a future lesson of this unit. 